\title{
On the question of the research methodology of the Russian political elite (on the example of the Republic of Tuva)
}

\author{
Saidash Sadi, Yaroslav Nekrasov, Matvey Pyatkov, and Sergey Chirun \\ Kemerovo State University, 650000, Krasnaya Str., 6, Kemerovo, Russia
}

\begin{abstract}
The article is devoted to the analysis of the transparency of concepts known in modern political science to the study of Russian regional political elites, using the example of the Republic of Tuva. In the process of work, the authors used qualitative methods: in-depth interviews, expert survey, focus groups; quantitative methods: sampling method, questionnaire survey, event analysis, content analysis. The authors focused their attention on such characteristics of the regional political elite as: clientelism, closeness, corporate, particular orientation.

The authors come to the conclusion that an increase in the degree of efficiency of the regional elite can be achieved subject to the modernization of personnel policy, the transition from a clan-related system of relations to the implementation of effective management based on an entrepreneurial system.
\end{abstract}

\section{Introduction}

Although the main domestic political issues in our country are decided by the Federal Center, their implementation is largely due to staffing at the regional level. The structural composition, qualitative characteristics, mechanisms and channels for recruiting the regional political elite largely determine the peculiarities of the course of the political process at the regional level, and also determine the specifics of the diversification of the political and cultural development of Russian regions. Therefore, the study of current sociopolitical processes in our state and the analysis of regional features of political and socioeconomic development are impossible without researching both federal and regional characteristics of the political elite. The term «elite» was first introduced by V. Pareto. The presence of an elite, he considered a universal characteristic of any system. In his opinion, the elite should include those who, due to their psychological characteristics, occupy the most significant statuses in politics.

Similar ideas were developed in his studies by R. Michels, the father of theory of the "iron law of oligarchy". According to the concept of R. Michels, any elite always gives priority to their own interests, which differ from the interests of the communities they govern. The main goal is to retain power.

K. Mannheim's typology includes two types of elites. He refers to the first type as integrative (whose functions are to integrate the harmonization of public interests), and to the second - sublimative (their task is to sublimate the demands of the masses and articulate 
them in a conventional way). For Charles Mills, belonging to the ruling elite means the highest positions in the state civil and military service, as well as in large financial and industrial corporations [1].

According to the criterion of the solidity of the elite, S. Keller divides the elite into strategic and segmental.. The first is this elite influencing the whole country. The segmental elite is, in fact, the regional elite [2, P.21].

The regional political elite is not homogeneous, but represents different groups with their own interests.

An analysis of the structures and mechanisms of the formation of regional political elites in modern Russia makes it possible to more correctly determine the predictive characteristics of the political process, to identify potential threats and new opportunities for regional development.

\section{Materials and Methods}

The methodological basis of the research is presented by a polyparadigmatic approach. The following research methods were used: general scientific methods (analysis, synthesis, deduction, induction); qualitative methods: in-depth interviews, expert survey, focus groups; quantitative methods: sampling method, questionnaire survey, event analysis, content analysis.

The structural-functional approach we use allowed us to interpret the elite as an integral phenomenon, gave us the opportunity to present the theoretical aspects of the study of the political elite of Tuva.

When analyzing the channels and technologies of elite genesis, special attention was paid to the personal characteristics of regional leaders, to the features of regional political culture, as well as technologies used by the regional elite in interaction with both regional political players and the federal center [3, P.137-152]. All this made it possible to predict the patterns of transformation of the regional political elite.

The regional political elite controls the main resources of the region, which allows them to make key decisions at the regional level. It is represented by formalized and informal elite groups participating in the struggle for access to political resources.

R. Dahl considered elite competition as an essential element of the existence of a democratic regime [P.24].

Competition between subelite groups is not synonymous with the normative ideal of democracy. Moreover, a situation may arise in which small groups, rather than large ones, have advantages, and this will allow them to impose solutions on society that meet exclusively their narrow corporate interests.

Thus, it is representatives of small groups that are usually represented in power structures, while democratic strata turn out to be political outsiders. Once having mastered positions of power, small groups will no longer voluntarily surrender power, but will use non-democratic methods to retain vital resources and privileges.

For example, the former party and Soviet nomination turned out to be quite successful in the process of evolutionary transit. This is due to the fact that this category in the context of political transit and quasi-market relations received additional opportunities for enrichment. Moreover, in fact, this elite begins to slow down the reform process in order to maintain the situation of «frozen» transit, as the main condition for extending its further parasitic existence.

It follows from this that liberal elites who came to power in the first stage of political transition (for example, the Russian systemic liberals) lose interest in continuing reforms, and even on the contrary, they are motivated to maintain their own power monopoly, which leads to their close and even reactionary [5, P. 54-74]. 
When analyzing the post-Soviet elite, political scientists are actively exploring such a social community as clientele and clan groups.

OV Kryshtanovskaya, distinguishes clans, cliques, strategic groups, as well as pressure groups among the elites [6, P. 81]. Due to the regional specifics of various regions of Russia, there is a significant regional differentiation of recruiting mechanisms for regional elites.

Thus, Professor M. Kh. Farukshin pointed out ethnicity, professional merits, education, family ties, gender, age as the basic structural units of regional elitogenesis. Exploring the regional ethnic elite, he draws attention to its rural origin. In his opinion, this negatively affects the problem of the democratic development of regions, since such a culture includes the traditional norms of reverence for rank and neo-patrimonialism. [7, P. 67].

The structural analysis of the regional political elite is carried out by R.F. Turovsky, exploring the competition of status positions among representatives of various ethnic groups, which is especially important for national republics [8].

A.I. Solovyov investigates such trends of domestic elitogenesis as: shadowing (shadow connection between business and government); ethnization (promotion of representatives of a certain ethnic group into power); corporatization (opposition of corporate group interests to the interests of society and the state); clanification (the use of administrative resources in the interests of relatives) [9, P. 135-147].

In terms of concept of R.R. Gallyamov, the system of power in the Tyva Republic, as well as in Bashkortostan, can be conditionally defined as «an authoritarian and nomenclature political regime» [10, P.58]. In addition, regional ethnocratic regimes usually tend to form patronage-clientelistic and clan channels for recruiting elites.

So for Tuva, the clan principle is a typical form of the feudal-patriarchal organization of regional power. However, in the opinion of O. V. Gaman-Golutvina, kinship ties are no longer the basis of the clan organization. The essence of modern clans, in her opinion, is represented by such characteristics as: clientelism, closeness, corporate, particular orientation. She proposed the concept of two types of social development: an innovative type of development (ITD) and a mobilization type of development (MTD) of the relationship between the process of social development and the modeling of elite formation [11, P. 67-85].

In this sense, ethnocratic regimes oppose the principles of democracy and act as instruments for increasing and maintaining the ruling positions of the ethnoelite. Gelman V.Ya., Typologizes regional political regimes, according to the criterion of the dominant political actor. Under the condition of an unconditional political dominant, the function is a monocentric regime in which informal institutions predominate, while in a polycentric regime, on the contrary, formal institutions predominate [12, P. 122-158].

Professor A.L. Popov argues that a bipolar split of elites is quite likely for monoregions. On the contrary, the regions in which various economic resources are represented tend more toward inter-elite polycentrism. It is based on the compromise strategies of the negotiation process, and not the struggle that results in a «zero sum», when one participant in the confrontation wins exactly as much as the other loses. [13, P. 15-16].

From the point of view of R.R Gallyamov, the formation of ethnocracy in the national republics of post-Soviet Russia was due to several reasons, the main of which are associated with the tasks of retaining power by elites representing the titular ethnic groups. In addition, ethnocratic elements of power help to create shadow channels of elite recruitment based on patronage-clientelist, clan, ethnocultural and family-clan ties [14, P. 36-37]. For example, in Tuva, young strangers, people are usually identified by their kinship or clan affiliation [15, P. 126]. In this political culture, a person as a unique personality is actually not perceived. And only in the context of the achievements of the ancestors does it acquire its status. Clannishness can be interpreted as immoral nepotism. 


\section{Results and Discussion}

One of the ways to develop regional elites can be a structured constellation of elites. As a hypothesis, we can assume that clan elites characterize primarily the system of power of ethnic republics in which a monocratic elite has developed. From the point of view of the theory of traits, it can be argued that the elite of Tuva is characterized by the following ethnopsychological features: pronounced tribal and ethnic affiliation; kinship and clan relations; the ability to adapt to the harsh nature and the ability to endure hardships, emotional and volitional stability, tolerance, unpretentiousness, perseverance, sincerity, politeness, respect for power, striving for balance and harmony. Thus, according to the results of our research, the popularity of the values of conservatism, patriotism, material equality and economic self-sufficiency (autarky), as well as the desire for state regulation of the economy, is typical for Tuvan society.

The elite of Tuva was initially characterized by patrimonism and loyalty towards the federal center. However, in a situation where national elites «can choose a strategy of loyalty and submit to the demands of the federal authorities. The consequence of this choice may be the out of control of ethnic minorities, for whom the loss of preferences is painful». [16, P. 53]

Thus, kinship ties are the leading channel for recruiting clan elites in Tuva. However, a large breadth and mass scale of incorporation is achieved on the basis of ethnic channels of informal elite recruiting. In the Republic of Tyva, with the existing division of the population into titular and non-titular nations, these types of elite identity are becoming the most common. Of particular importance in the regions are oligarchic elite groups associated with power and rent extraction technologies [17, P. 81-99]. The characteristics of the latter are determined primarily by the economic specialization of Tuva.

Meanwhile, the sphere of interests of these groups is not limited exclusively to economics. These actors not only actively lobby their economic interests in the regions, but also regularly invade the political sphere. Moreover, it is the presence of a stable conditionality of economic opportunities and political resources that enables researchers to define these elites as oligarchic [18, P.110-125]. A specific feature of these elites in modern Russia is their closest incorporation with federal political elites or power structures. It is the economic elites that should play a decisive role in the modernization of Tuva - as a selfsufficient region of Russia, based on a unique identity, mobilizing the existing socioeconomic potential without threatening the integrity of Russia. However, Professor A.S. Zheleznyakov draws attention to the slowdown of modernization processes in the regions of Russia, which began in 2008.

As the reasons for this phenomenon, he considers both external and internal factors, and he comes to the conclusion that the modernization of the Russian regions «is carried out spontaneously, fragmentarily, in contrast to the regions and in general ineffective, not providing a proper improvement in the quality of life of the majority of the population» $[19$, P. 186-191].

The development of regional elites in Tuva over the past decade has been characterized by two opposite trends: consolidation and fragmentation of elites. The acquisition of power determines the consolidation of the elite around its leader, but over time, contradictions arise between members of the elite, provoked by differences in their position in relation to the sources of administrative and material rent. Conflicts that arise regularly appear in public space. To resolve these conflict situations, the elites have to turn to the federal center.

This circumstance is associated with the peculiarities of the political culture of the population of Tuva, which is dominated by traditions of loyalty to the authorities and territorial clannishness [20, P. 120-128]. 
For the Republic of Tuva, an increase in the efficiency of the regional elite can be achieved subject to the modernization of personnel policy, a transition from a clan-related system of relations to the implementation of effective management. However, there are objective factors that hinder the modernization of the political regime in the Republic of Tuva: the crisis state of the economy, which determines the mobilization nature of economic development, and the need for a «strong hand». The lack of the skills of a participatory political culture among the majority of the population of Tuva, which is a culture of activist political participation, determines the conditions for a socio-political lag in the development of the region [21, P.20-30].

Moreover, in electoral autocracies, electoral procedures are not capable of ensuring the rotation of the elites. On the contrary, their purpose in such a system is to create the appearance of the legitimacy of the «autocrat to power through the voting procedure» [22, P. 76-91].

This is what determines «the complexity of building a path to genuine modernization, especially in the modern information world, since this path must also take into account the presence of institutional pathologies associated with previous unsuccessful attempts at mobilization breakthroughs» [23, P. 42-62].

\section{Conclusion}

1.Based on the analysis of the main approaches to defining the essence of regional political elites, the following definition can be proposed: the regional political elite is a narrow group with significant: administrative; financial; managerial; resources, which allows it to directly make or influence the adoption of the most important decisions for the politics and economy of the region.

2. The regional elite includes representatives of various subelites. Our research shows that the regional elite of Tuva is divided into groups of formal and informal types. The formal party-bureaucratic elite group. The informal elite includes clans (compatriot and ethnic), as well as clientele. At the same time, the subelites will be distinguished by high mutual permeability, and their representatives will have significant horizontal mobility.

3. Analysis of the main characteristics of domestic political elites at the present stage allows us to assert that the process of their formation continues at the present time. During the period of their formation and development, they were unable to acquire relative cohesion, integrity and unity. These tendencies are conditioned by the peculiarities of the historical period in which the transformation of political elites is taking place: the centralization of federal power is increasing, the political activity of the population is gradually weakening, a model of behavior of the actors of the regional elite oriented towards loyalty to the federal center is being formed.

4. The political elite of Tuva in the crisis moments of modern political history show their inability to solve the problems of confrontation between rival groups on their own. Regional political crises in the republic are resolved thanks to the interventions of the federal government.

5. The prospects for the political development of the Republic of Tyva, the corps of its political leaders, elites, as well as civil society institutions will largely depend on the balance of positive and negative trends in the dynamics of the regional political system.

\section{References}

1. C. W. Mills, The Power Elite. New York (1959)

2. S. Keller, Beyond the Ruling Class. Strategic Elites in Modem Society (1969) 
3. T. N Litvinova, Policy. Political Studies, 2, 137 (2020)

4. R. Dahl, Polyarchy: participation and opposition, (2010)

5. I.A. Matveev, World of Russia, 1, 54 (2019)

6. O.V. Kryshtanovskaya, Anatomy of the Russian elite (2005)

7. M. Kh. Farukshin, Political Studies, 6, 67 (1994)

8. R. F. Turovsky, Political regionalism (2006)

9. A.I. Soloviev, Policy. Political Studies, 6, 135 (2020)

10. R.R. Gallyamov, Elite of Bashkortostan. Political and confessional dimensions (2006)

11. O.V. Gaman-Golutvina, Polis, 6, 67 (2008)

12. V.Ya. Gelman, Political Almanac of the Kama region. Perm, 1, 122 (2001)

13. A .L. Popov The ruling elite as a subject of the regional political process (on the example of the Republic of Sakha (Yakutia)) (2004)

14. R. R. Gallyamov, Political elite. Ethnicity. Citizenship (2004)

15. Ch. K. Lamazhaaa, Tuva between the past and the future (2011)

16. S. N. Shkel, Regions. Policy. Political Studies, 1, 49 (2019)

17. V. S. Martyanov, Policy. Political Studies, 4, 81 (2016)

18. S. Yu. Barsukova., E. V. Denisova-Schmidt, Policy. Political Studies, 3, 110 (2020)

19. A.S. Zheleznyakov, Policy. Political Studies, 4, 186 (2017)

20. A. Russo, C.Dufy, Mir Rossii, 4, 120(2018)

21. N. I. Lapin, V. A. Ilyin, M. V. Morev, Sociological research, 2, 20 (2020)

22. E. V. Sirotkina, S.A. Karandashova, Policy. Political Studies, 6, 76 (2017)

23. N.M. Pliskevich, World of Russia, 2, 42 (2019) 